4 Chandra D, Bonomi PD, Rossof AH, et al. Phase II trial of mitomycin C, methyl CCNU and 5-fluorouracil (5-FU) in advanced colorectal carcinoma. Proceedings of the American Society of Clinical Oncology $1979 ; 20: C 129$.

${ }^{5}$ Lokich JJ, Skarin AT, Mayer RJ, et al. Lack of effectiveness of combined 5 -fluorouracil and methyl CCNU therapy in advanced colorectal cancer. Cancer 1977;40:2792-6.

(Accepted 6 fune 1980)

Department of Medical Oncology, Hackney and St Bartholomew's Hospitals, London

A A EPENETOS, MB, MRCP, registrar (now clinical research scientist, Imperial Cancer Research Fund Laboratories, London WC2A 3PX)

C AMOS, MB, senior house officer

C COLLIS, MA, MRCP, registrar (now lecturer in oncology, Institute of Cancer Research, Royal Marsden Hospital, Sutton, Surrey)

M SLEVIN, MB, MRCP, registrar

A ROHATINER, MB, MRCP, registrar (now research fellow in medical oncology, St Bartholomew's Hospital, London EC1A 7BE)

H BAILLE-JOHNSON, MB, MRCP, registrar (now registrar in radiotherapy and oncology, Middlesex Hospital, London W1P 7PN)

J PITTS, MB, MRCP, registrar

P F M WRIGLEY, PHD, FRCP, consultant

\section{Extreme eosinophilia due to common streptococcal infection in an adult}

The occurrence of severe leucocytosis with eosinophilia in blood and bone marrow together with lymphadenopathy during the course of a common infection such as sore throat is an unusual phenomenon and not known to occur in adults. We describe such a case, in which extreme eosinophilia developed in an adult.

\section{Case report}

A 27-year-old man was admitted to this department in June 1979 with fever $\left(38.8^{\circ} \mathrm{C}\right)$, malaise, anorexia, and cervical lymphadenopathy. He had a sore throat, and examination showed acute tonsillitis. Slightly to moderately enlarged lymph nodes were palpable in cervical, supraclavicular, and submandibular areas as well as a solitary enlarged lymph node in the right axilla. There was no enlargement of the liver or spleen. Laboratory examination showed (figure) hyperleucocytosis with extreme eosinophilia (white cell count $28 \times 10^{9} / 1\left(28000 / \mathrm{mm}^{3}\right)$, eosinophils $23 \times 10^{9} / 1\left(23000 / \mathrm{mm}^{3}-85 \%\right)$, neutrophils $4 \%$, lymphocytes $10 \%$, monocytes $1 \%$ ); packed cell volume $45 \%$; haemoglobin $15.7 \mathrm{~g} / \mathrm{dl}$; erythrocyte sedimentation rate $13 \mathrm{~mm}$ in first hour; and antistreptolysin 0 titre 625 Todd units; cultures from the throat yielded $\beta$-haemolytic streptococcus.

During the course of the illness the leucocytosis increased further to $64 \times 10^{9} / 1\left(64000 / \mathrm{mm}^{3}\right)$ with an absolute number of eosinophils of $56.3 \times$ $10^{9} / 1\left(56300 / \mathrm{mm}^{3}\right)$. Bone-marrow aspiration showed hyperplasia of white cell series with a predominance of eosinophils, both mature and immature. A Paul-Bunnell reaction, Casoni skin test, and Weinberg serological tests were negative. A chest $x$-ray film was normal, and no parasites were found in stools.

He had no history of allergic or other serious illness. Penicillin $4 \times 10^{6}$ units daily and streptomycin $1 \mathrm{~g}$ daily were started; after three days of treatment the temperature returned to normal, and the sore throat and enlarged lymph nodes subsided gradually and vanished in a few days. Serial examinations of peripheral blood showed that the number of leucocytes fell abruptly to normal (figure) and eosinophils fell to an absolute number of $0.91 \times 10^{9} / 1\left(910 / \mathrm{mm}^{3}\right)$ on the twenty-first day of admission. Three months later the patient had no abnormal clinical signs and his blood picture was normal (white cell count $7 \cdot 4 \times 10^{9} / 1\left(7400 / \mathrm{mm}^{3}\right.$ ) with an absolute number of eosinophils of $\left.0.222 \times 10^{9} / 1\left(222 / \mathrm{mm}^{3}\right)\right)$.

\section{Comment}

Several patients with severe eosinophilic leucocytosis, hepatosplenomegaly, bronchial asthmatic attacks, fever, and cervical lymphadenopathy have been described. ${ }^{12}$ Most have been children, and the symptoms were often attributed to parasitic infestation with, for example, Toxocara canis, Paragonimus westermani, and Ascaris.

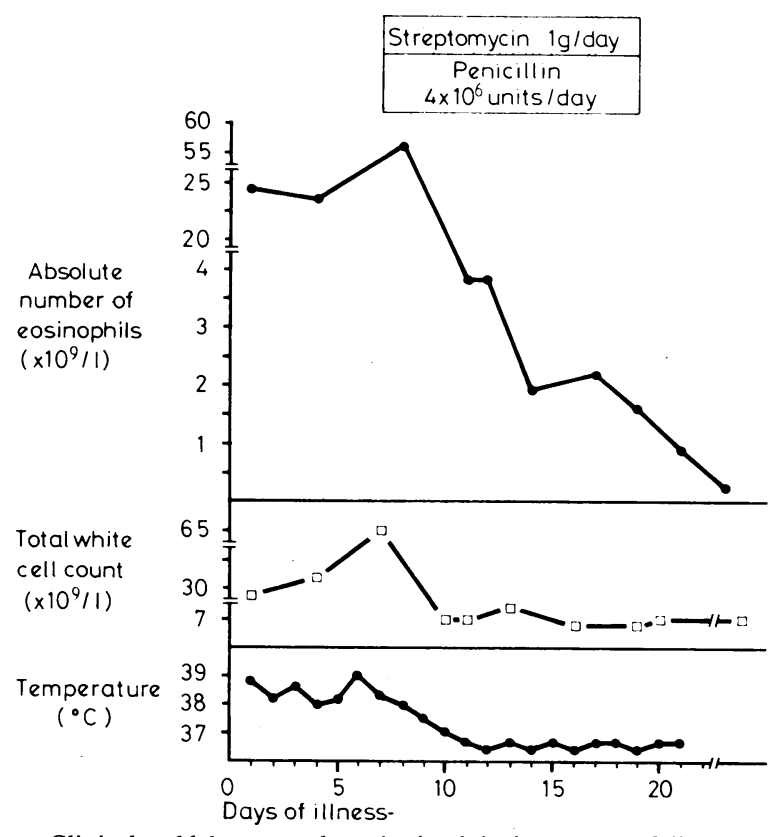

Clinical and laboratory data obtained during course of illness.

Certainly many other parasites, especially those invading the tissues, may produce severe eosinophilia in children and in adults. ${ }^{1}$ Persistent and pronounced eosinophilia in blood and bone marrow with extreme leucocytosis and visceral lesions also occurred in a syndrome of obscure aetiology described by Zuelzer and Apt. ${ }^{3}$ Such cases have also been reported by other authors but always in children. Scarlet fever is occasionally accompanied by slight eosinophilia during the convalescence period. ${ }^{4}$

Our case was unrelated to any of the above syndromes. We excluded Löffler's syndrome ${ }^{12}$ because of the absence of pulmonary symptoms and pulmonary infiltrations on $x$-ray films. From the clinical and laboratory data we also excluded other causes of eosinophilic leucocytosis with fever and lymphadenopathy such as chronic myelocytic leukaemia, Hodgkin's disease, and tropical eosinophilia. The absence of any evidence of previous allergic disorders and the return of the eosinophils to normal counts, plus the absence of splenomegaly, make the possibility of a concurrent allergic condition or inherited eosinophilia improbable.

Our case represents an unusual example of eosinophilic leucocytosis with an extremely high eosinophil count and concomitant hyperactivity of bone marrow after a common streptococcal infection. Lymphadenopathy was also an interesting feature.

There is evidence ${ }^{5}$ that in some persons with no previous allergic conditions appreciable eosinophilia associated with infections of the upper respiratory tract is likely to indicate a hyperimmune sensitivity reaction in response either to micro-organisms or to their products (not necessarily any specific infection).

1 Wintrobe MM. Eosinophilia. In: Clinical hematology. Philadelphia: Lea and Febiger, 1967:273-6.

${ }^{2}$ Hardy WR, Anderson RE. The hypereosinophilic syndromes. Ann Intern Med 1968;68:1220-8.

${ }^{3}$ Zuelzer W, Apt L. Disseminated visceral lesions associated with extreme eosinophilia. Pathogenic and clinical observations on a syndrome of young children. Am $\mathcal{F}$ Dis Child 1949;78:153.

${ }^{4}$ Rammelkamp CH. Hemolytic streptococcal infections. In: Wintrobe MW, Thory GW, Adams RD et al, eds. Harrison's principles of internal medicine. Tokyo: McGraw-Hill Kogakusha, 1977:781.

5 Any questions? $\mathrm{Br} M e d \mathcal{F} 1968 ; \mathrm{ii}: 481$.

(Accepted 12 June 1980)

2nd Department of Medicine, University of Athens Medical School, Hippocration General Hospital, Athens (610), Greece

A D EFSTRATOPOULOS, MD, associate professor of internal medicine A N SPANTIDEAS, MD, senior registrar of internal medicine Z D KOMNINOS, $M D$, professor of internal medicine 